\title{
SCOUR IN FRONT OF THE LATERAL INTAKES DUE TO USING SINGLE ROW OF SUBMERGED VANES
}

\author{
Samir A. S. Ibrahim \\ Hydraulics Research Institute, National Water Research Centre, Egypt
}

\begin{abstract}
Submerged vanes can be used to create sufficient depth for navigation, to mitigate bank erosion or to divert sediment away of lateral intakes. Besides these intended effects, submerged vanes also produce local scour, which may interfere with the intended morphological correction and which is relevant to the structural stability of the vanes. The present paper shows an experimental study that was executed in order to investigate the local scour that induced in front of the lateral intakes due to using a single row of submerged vanes to minimize the sediment that entered the intake channel. Sixty experiments were carried out using a single row of vanes, considering various vane heights, angles, and positions under different flow conditions. A case of flat floor without vanes was included to estimate the influence of the submerged vanes on the scour in front of the diversions. Obtained results were analyzed and graphically presented, and also provide simple formulas to compute the maximum scour depth in vicinity of the single submerged vanes at different flows entering the lateral intake.

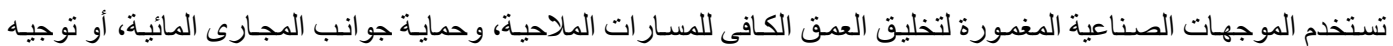

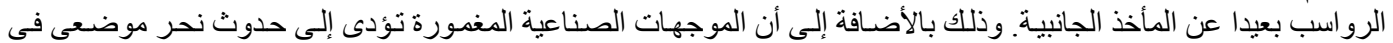

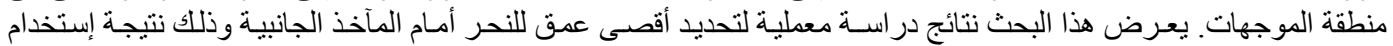

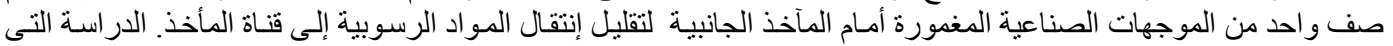

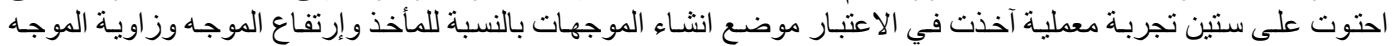

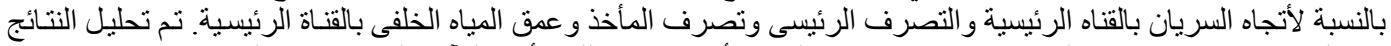

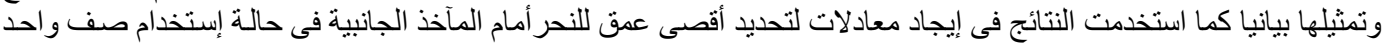

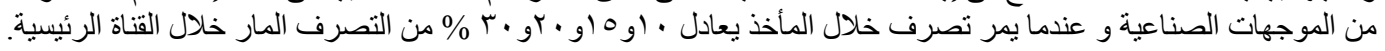

Keywords: Local Scour, Submerged vanes, Lateral Intake, Physical model, Sedimentation

\section{INTRODUCTION}

A submerged vane (Figure 1) is an effective measure for sediment management in alluvial rivers. By installing a number of vanes on the streambed at an angle to the flow, the flow pattern down stream the vane is changed and the shear stress on the channel bed is redistributed. As a result, the bed material is transported transversely in a channel cross section. With proper configuration of the vanes, a certain portion of the streambed affected by the vanes can practically be modified into any designated profile that is favored for the management of the river. Applications of vanes include prevention of bank erosion (Odgaard and Kennedy 1983; Wang and Odgaard 1993; Johnson et al. 2001), deepening channels for navigation (Odgaard and Spoljaric 1989; Odgaard and Wang 1991b), and sediment exclusion at water intakes (Wang et al. 1996; Barkdoll et al. 1999; Michell et al. 2006).

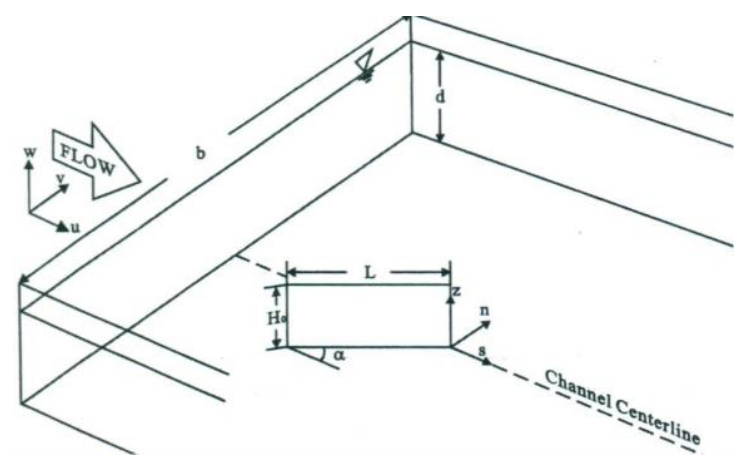

Fig. 1 Definition sketch of a submerged vane

The concept behind vanes is that they set up a tip vortex similar to that of an airplane wing. The combination of vane induced circulation and stream wise velocity causes a helical motion, or vortex, in the flow downstream the vanes, as shown conceptually in Figure 2 for flow past a diversion. The vortex extends downstream, gradually widening 
and decaying in strength due to the water viscosity. The helical flow created by the vortex causes transverse shear stresses on the riverbed, resulting in sediment transport in a direction transverse to the flow direction. The transverse shear stresses causes sediment be picked up on the vane's suction side and deposited on the pressure side. Consequently a scour trench forms along the downstream side of the vane (Figure 2 ). By placing vanes in rows, the scour trench can be extended to cover a comparatively wider area (Odgaard and Wang 1991,a,b). This scouring action makes vanes useful as a means for minimizing bedsediment ingestion into diversions from alluvial channels. They have been used for this purpose at about a dozen lateral diversion water intakes for thermal power stations and municipal water supply facilities. In this current study, scour in front of the intake channel that induced due to a single row of submerged vanes has been studied experimentally in order to predict maximum scour depth, affected area and mean depth of erosion. Experimental study is used to develop a formula that serve the determination of a safe foundation depth for the submerged vanes.

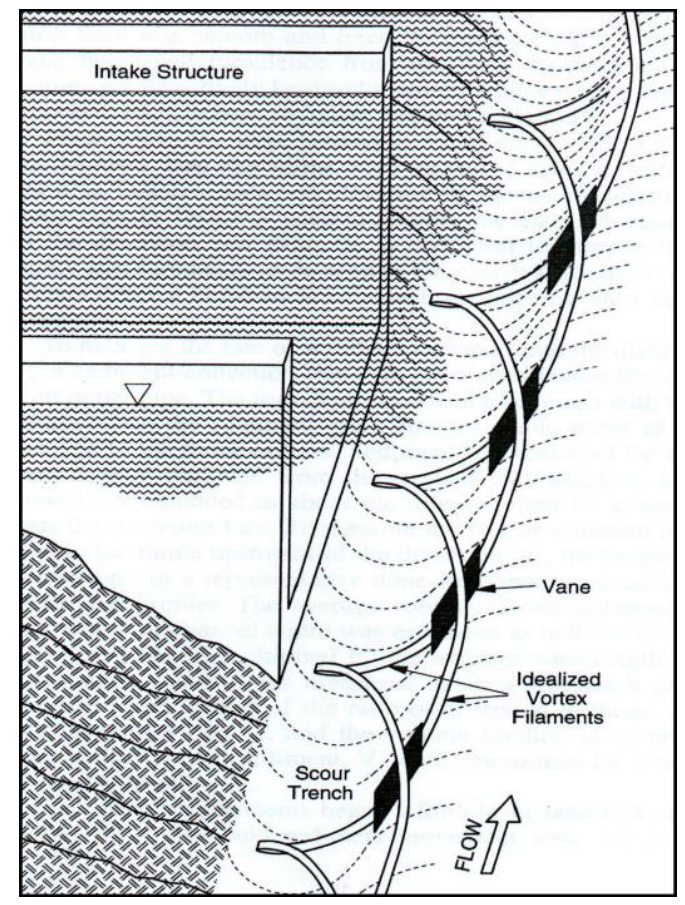

Fig. 2 Conceptual flow pattern and scour trench due to submerged vane

(After Brian. D. Barkdool, 1999)

\section{LABORATORY EXPRIMRNTS}

Figure (3) shows the flume layout and the apparatus used in the present study. The main flume is $0.60 \mathrm{~m}$ wide, $0.60 \mathrm{~m}$ deep and $20 \mathrm{~m}$ long. The lateral-intake channel is $0.20 \mathrm{~m}$ wide, $0.60 \mathrm{~m}$ deep, and $3.0 \mathrm{~m}$ long and is fitted at a $90^{\circ}$ to the main flume. The flume is constructed of bricks sealed with smooth cement mortar. The flume consists of head and tail tanks and main, lateral and by-pass channels. Two centrifugal pumps are used; the first is to supply water to the head tank from the ground sump, and the other is submerged in the intake channel to deliver water to the bypass-channel. Water is controlled using a control valve installed on the pipe connected to the feeding pump. The head tank has a weir, which is calibrated to measure the flow that feeds the flume, and a gravel box, which is used to provide an even flow distribution across the flume. The flow enters the flume through an inlet screen to absorb any water eddies.

The model bed is made of smooth cement-sand mortar, overlaid on a $0.5 \mathrm{~m}$ layer of sand. To represent the movable bed, a $5 \mathrm{~m}$ reach of the flume in front of the intake is filled with a $0.15 \mathrm{~m}$ deep layer of a uniform PVC material with $\mathrm{d} 50=2.5 \mathrm{~mm}$, and a specific weight of $1080 \mathrm{~kg} / \mathrm{m} 3$. Precise point gauge is installed to measure the bed level and the water depth. The gauge is mounted on carriage moving in the flow and the perpendicular directions. Downstream water depth is controlled using a hinged tail gate. The intake channel is located $8.0 \mathrm{~m}$ downstream the flume inlet. The fixed-floor elevation of the intake was leveled with the movable bed in the flume. A point gauge was used to monitor the bed topography on a grid $20 \mathrm{~cm} \mathrm{x} 10 \mathrm{~cm}$ (sometimes $5 \mathrm{~cm} \times 10 \mathrm{~cm}$ depending on the shape) after each run. The measurements covered the area in front of intake channel. The grid pattern was sufficiently dense to obtain accurate bed topography at the end of each experiment. Photo (1), and (2), shows the tested cases.

\section{EXPERIMENTAL PROCEDURE}

To study the scour in front of intakes due to using a single row of submerged vanes, flume flow was sub-critical. The discharge was kept constant at 25 $\mathrm{L} / \mathrm{sec}$. The intake discharge was varied to investigate four discharge ratios (Qr) with respect to the flow in the main channel $(\mathrm{Qr}=0.10,0.15,0.20$, and 0.30$)$. The tail water depth is fixed and equal to $0.12 \mathrm{~m}$. Four vanes were installed in one row. The centerline of the row was perpendicular to the main flow direction. The vanes were made of a steel plate of 2 $\mathrm{mm}$ thick and $10 \mathrm{~cm}$ long. The row of vanes was fixed on a $2 \mathrm{~mm}$ thick steel plate. The distance between each two vanes was $10 \mathrm{~cm}$, and the distance between the vane and the flume wall was $7 \mathrm{~cm}$.

Figure (4) shows the proposed alignment of the row of vanes which was located at five positions with respect to the intake bed width, bv/bd $=0.0,0.5$, 1.0, 1.5, and 2.0. To get the effect of the position, the angles of vanes with the main flow direction were changed five times, $\alpha=10^{\circ}, 20^{\circ}, 30^{\circ}, 40^{\circ}$, and $50^{\circ}$. At the above mentioned angles of vanes, four heights of vanes are used, $\mathrm{Hv} / \mathrm{Yt}=0.2,0.3,0.4$, and 0.5 . Some of these different experimental arrangements are 
used to determine the maximum scour in front of the intake channel in case of using a single row of vanes with different angles, heights, and at different positions.

Sixty runs were conducted including four runs without vanes to be used as a reference case. For each run, the backwater feeding is started first until its depth reaches higher than the required downstream depth, Yt. Then the upstream feeding is started to adjust the tail water depth and the tail gate is screwed gradually until the required depth is reached.

After several trials, a two-hour period was selected as a constant time for all runs. After the running time, the run was stopped and the flume was drained. The expecting scouring area was recorded with a precision point gauge to monitor the bed topography on a grid $20 \mathrm{~cm} \times 10 \mathrm{~cm}$. To estimate the maximum scour, a finer grid $(5 \mathrm{~cm} \times 10 \mathrm{~cm})$ was sometimes used depending on the shape of bed topography.

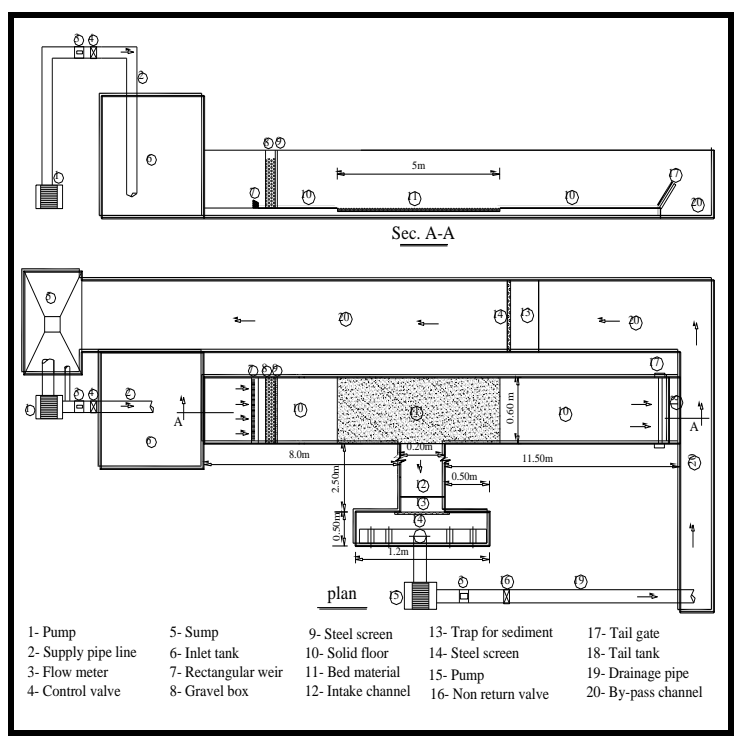

Fig. 3 Flume layout

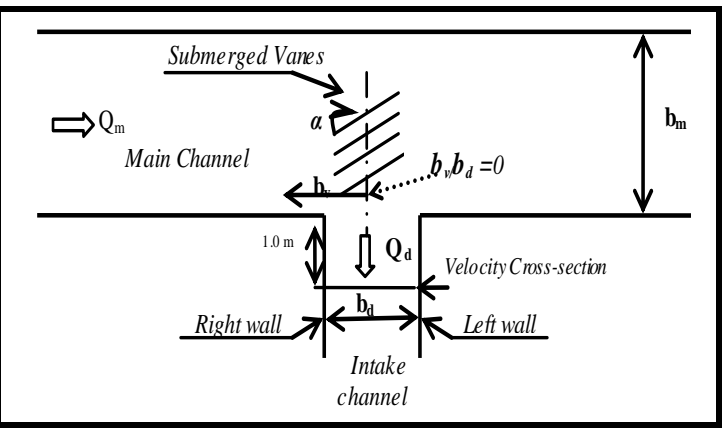

Fig. 4 Layout of the vanes

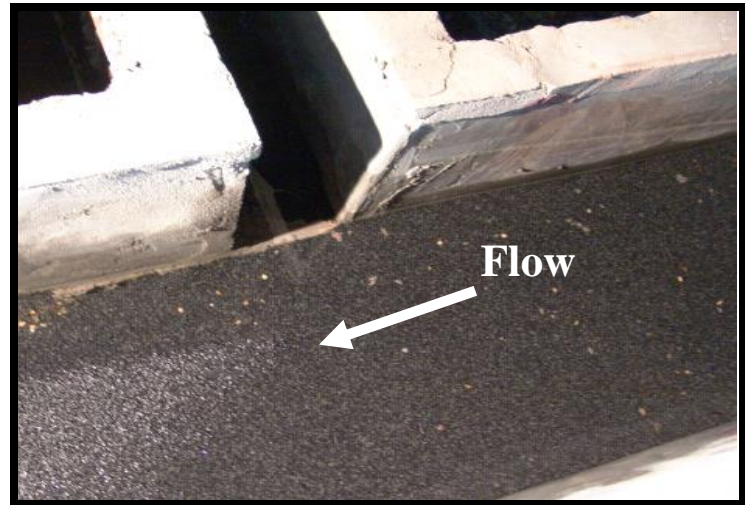

Photo 1 Flat floor without vanes

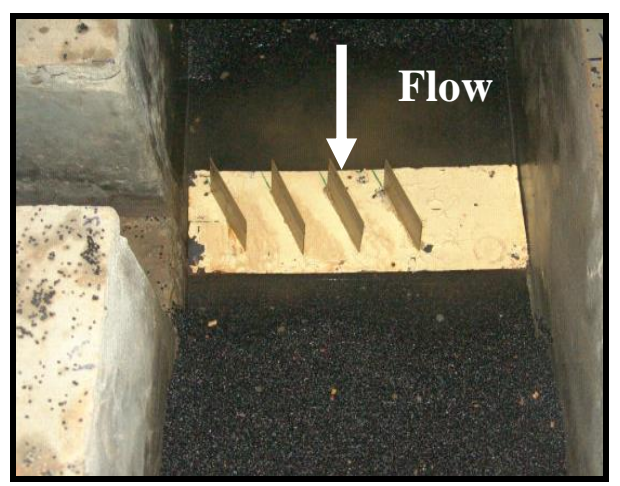

Photo 2 A single row of vanes

\section{RESULTS AND DISCUSSION}

To estimate the maximum scour in front of the intake channel in case of using a single row of vanes the following dimensionless parameters were used. (ds/dsw, bv/bd, $\alpha, \mathrm{Hv} / \mathrm{Yt}$, and Qr). Based on the experimental measurements, the effect of using a single row of vanes on the maximum scour depth in front of the intake (ds), under different values of discharge ratios (Qr), are presented by means of graphs.

\subsection{The effect of $b_{v} / b_{d}$, on $d_{s} / d_{s w}$}

- At most used ratios of Qr and bv/bd, the values of ds/dsw were more than one.

- Using of the submerged vanes lead to rapid increase in the scour depth in front of the intake channel as bv/bd decrease for the value of Qr less or equal to 0.15 .

- For all the tested values of Qr, the value of $\mathrm{ds} / \mathrm{dsw}$, decreased as the value of $\mathrm{bv} / \mathrm{bd}$, increased.

- The value of bv/bd equal 0.0 gave the maximum ds/dsw values, while at the value of bv/bd equal 2.0 gave the minimum $\mathrm{ds} / \mathrm{dsw}$, values.

- For the value of Qr equal to or higher than 0.2 the value of bv/bd has a minor negligible effect on the value of ds/dsw, Fig. (5). 


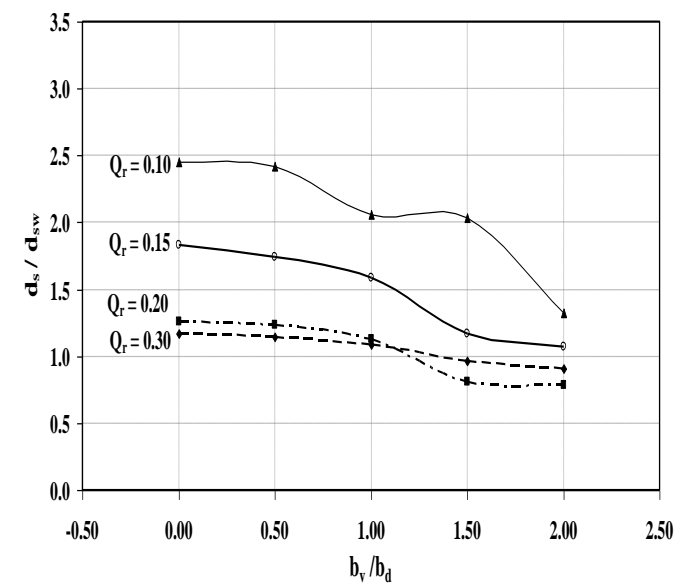

Fig. 5 Relationship between ds/dsw and bv/bd, for different Qr

\subsection{The effect of $\alpha$, on $\mathrm{ds} / \mathrm{dsw}$,}

- The results showed that for all values of $\alpha(\alpha=$ $10^{\circ}, 20^{\circ}, 30^{\circ}, 40^{\circ}$, and $\left.50^{\circ}\right)$ and $\mathrm{Qr}(\mathrm{Qr}=0.10$, $0.15,0.20$, and 0.30 ), the values of $\mathrm{ds} / \mathrm{dsw}$, were more than one.

- For the value of Qr, equal or less than 0.15 the value of $\mathrm{ds} / \mathrm{dsw}$, increased as the value of $\alpha$, increased. However for the value of Qr, equal 0.2 , almost, there is no effect of $\alpha$ on the $\mathrm{ds} / \mathrm{dsw}$ value, Fig. (6).

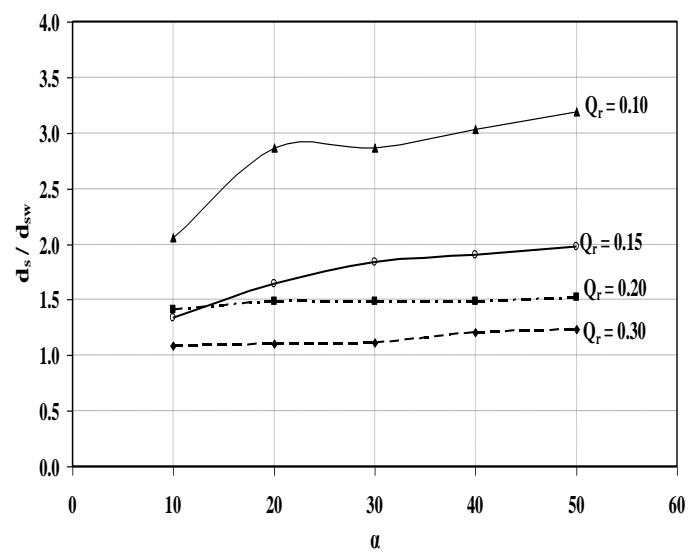

Fig. 6 Relationship between $d_{s} / d_{s w}$ and $\alpha$, for different $Q_{r}$

\subsection{The effect of $\mathrm{Hv} / \mathrm{Yt}$, on $\mathrm{ds} / \mathrm{dsw}$}

- The results showed that for all values of $\alpha(\alpha=$ $10^{\circ}, 20^{\circ}, 30^{\circ}, 40^{\circ}$, and $\left.50^{\circ}\right)$ and $\mathrm{Qr}(\mathrm{Qr}=0.10$, $0.15,0.20$, and 0.30 ), the values of $\mathrm{ds} / \mathrm{dsw}$, were more than one. This means that scour hole would have been formed.

- For all the tested values of Qr, the value of $\mathrm{Hv} / \mathrm{Yt}$ equal 0.5 , gave the maximum $\mathrm{ds} / \mathrm{dsw}$ values, while the value of $\mathrm{Hv} / \mathrm{Yt}=0.2$, gave the minimum ds/dsw, values.

- For the values of Qr, equal 0.2, the values of $\mathrm{Hv} / \mathrm{Yt}$ did not increase the values of $\mathrm{ds} / \mathrm{dsw}$.

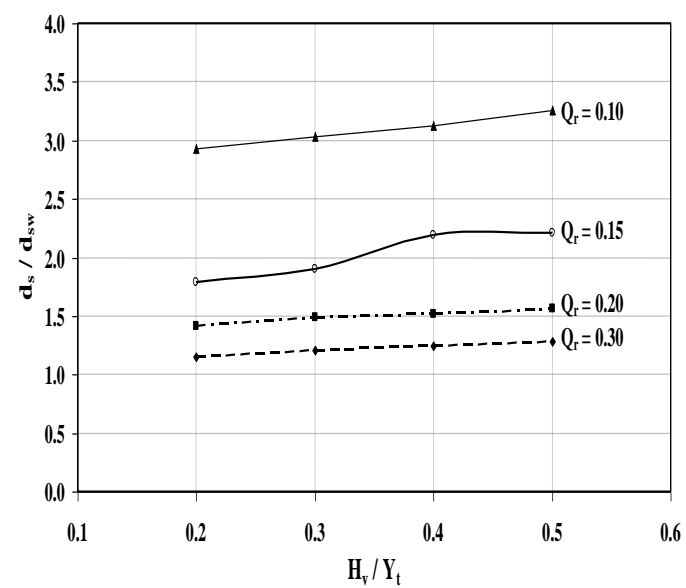

Fig.7 Relationship between $d_{s} / d_{s w}$ and $H_{v} / Y_{t}$, for different $Q_{r}$

\subsection{Bed Topography and Scour hole profile}

Bed topography contour maps show that, in all cases, the mean bed level had been lowered in the vicinity of the vane, but had been raised slightly above the initial level downstream the intake channel. The lowering of the mean bed level increased with increasing angle of vanes; Figures (8 and 9) show the contour maps without vanes and using single row of vanes for the selected case, respectively.

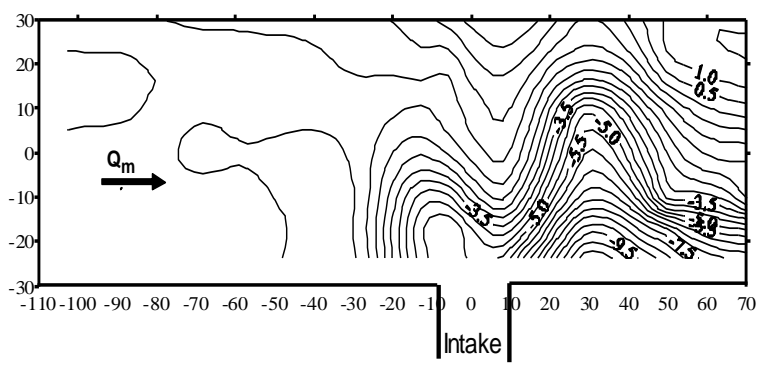

Fig. 8 The contour map without vanes $\left(b_{v} / b_{d}\right.$ $=0.50, \alpha=40^{\circ}, \mathrm{H}_{\mathrm{v}} / \mathrm{Y}_{\mathrm{t}}=0.4, \mathrm{Q}_{\mathrm{r}}=0.30$ )

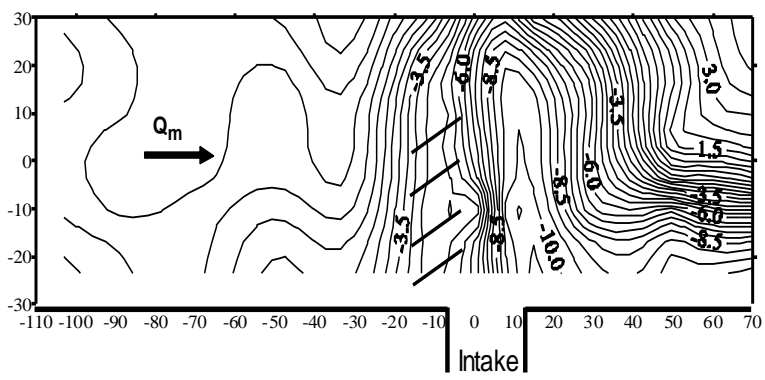

Fig. 9 The contour map using single row of vanes $\left(\mathrm{b}_{\mathrm{v}} / \mathrm{b}_{\mathrm{d}}=0.50, \alpha=40^{\circ}, \mathrm{H}_{\mathrm{v}} / \mathrm{Y}_{\mathrm{t}}=0.4, \mathrm{Q}_{\mathrm{r}}=0.30\right)$

The longitudinal sections along the center of the main channel and along the right, and the left third of the channel width were given. It was concluded that, using vanes increases the scour depths in front of the intake channel, but the position of scour changed from one case to another according to the submerged vane properties. Fig. (10 and 11), show the scour 
hole profiles for the selected case without vanes and using single row of vanes, respectively.

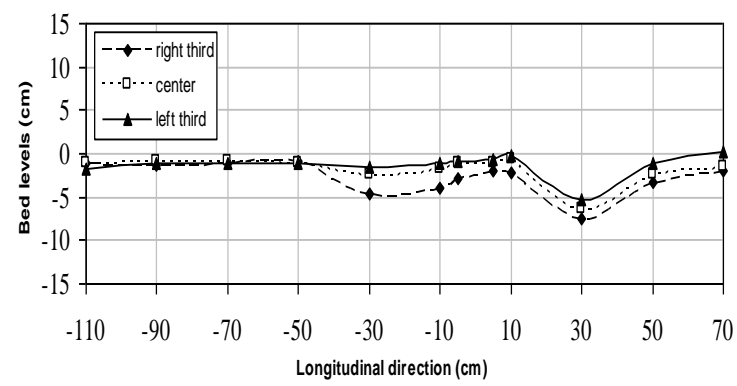

Fig. 10 Scour hole profile without vanes

$\left(b_{v} / b_{d}=0.50, \alpha=40^{\circ}, H_{v} / Y_{t}=0.4, Q_{r}=0.30\right)$

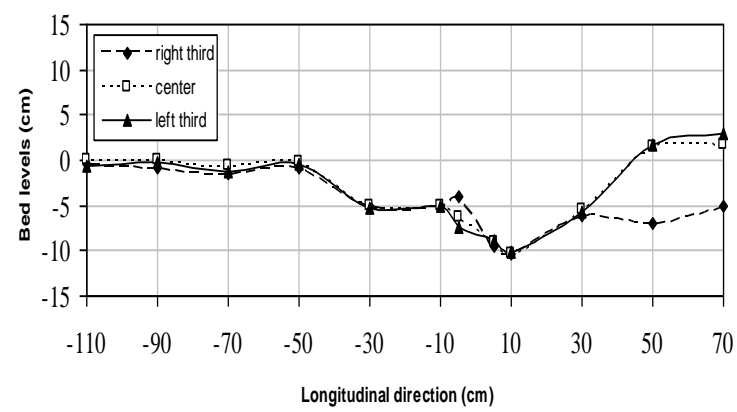

Fig. 11 Scour hole profile using single row of vanes $\left(b_{\mathrm{v}} / \mathrm{b}_{\mathrm{d}}=0.50, \alpha=40^{\circ}, \mathrm{H}_{\mathrm{v}} / \mathrm{Y}_{\mathrm{t}}=0.4, \mathrm{Q}_{\mathrm{r}}=0.30\right)$

The scour depth at an angle of 50 degrees has been found to be abruptly high for all vane heights, the maximum width of the scoured area is found to spread from 5 bd upstream to 3 bd downstream the intake channel and appears to increase with increasing vane height and vane angle with main flow direction. The maximum scour is located near the leading edge.

\section{EQUILIBRIUM SCOUR DEPTH}

The maximum scour depths in front of intake channel, ds, have been correlated with the flow depth, and the projected area of the vane, Ap (Ap = $\mathrm{Hv} \operatorname{Lv} \sin \alpha, \mathrm{Hv}$ denoting vane height above the undisturbed bed level, $\mathrm{Lv}$ denoting the vane length and $\alpha$ denoting the vane angle with respect to the main flow direction). Other parameters have not been considered because equilibrium live-bed scour does not vary with increasing velocity or grain size and depends only on flow depth for a given shape of obstruction, Vanoni, (1977).

In order to minimize the sediment transport that entered the intake channel, the best position of the single row of vanes was found at $\mathrm{bv} / \mathrm{bd}=0.5$. The sediment volume that entered the intake channel was the least quantity among the tested cases. See Fahmy, (2008).

Sets of test runs were carried out at bv/bd $=0.5$, Qr $=0.10,0.15,0.20,0.30$ and $\mathrm{Yt}=12 \mathrm{~cm}$. Each set of runs consists of 8 runs. Five runs were carried out at
$\mathrm{Hv} / \mathrm{Yt}=0.3$ and $\alpha=10^{\circ}, 20^{\circ}, 30^{\circ}, 40^{\circ}$, and $50^{\circ}$, respectively. Three runs were carried out at bv/bd $=$ 0.5 and $\mathrm{Hv} / \mathrm{Yt}=0.20,0.40$ and 0.5 , respectively. The result formulas were as follows:

$A$ - Case of $Q_{r}=0.1$

The resulting formula reads as:

$d_{s}=1.8925 \ln \left(\frac{H_{V} L_{V} \sin \alpha}{Y_{t}}\right)+8.1863$

The correlation coefficient is 0.8777 . Figure (12), shows the regression curve.

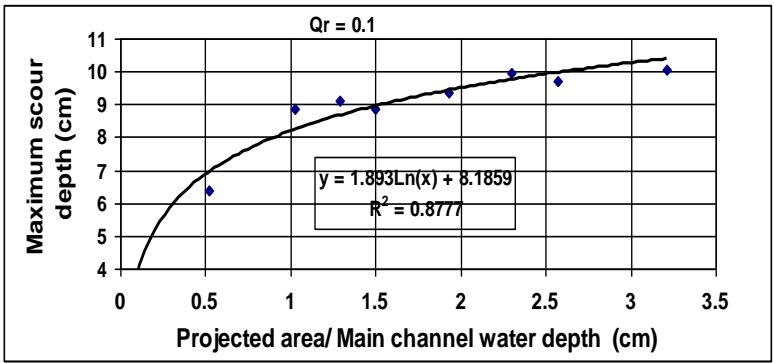

Fig. 12 Regression curve for maximum scour depth prediction $\left(\mathrm{b}_{\mathrm{v}} / \mathrm{b}_{\mathrm{d}}=0.5, \mathrm{Q}_{\mathrm{r}}=0.1\right)$

\section{$B$ - Case of $Q_{r}=0.15$}

The resulting formula reads as:

$d_{s}=6.8471\left(\frac{H_{V} L_{V} \sin \alpha}{Y_{t}}\right)^{0.2753}$

The correlation coefficient is 0.9742 . Fig. 13, shows the regression curve

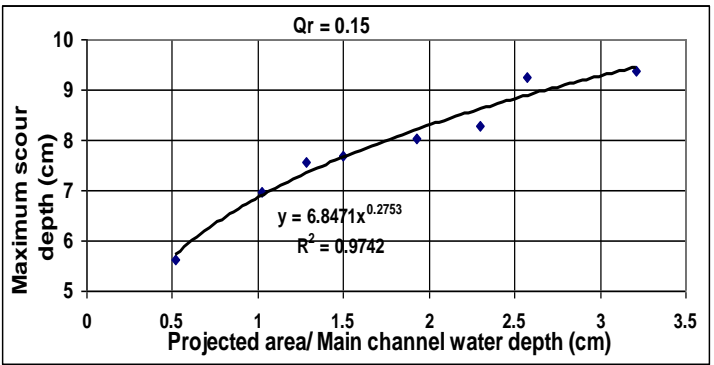

Fig. 13 Regression curve for maximum scour depth prediction $\left(\mathrm{b}_{\mathrm{v}} / \mathrm{b}_{\mathrm{d}}=0.5, \mathrm{Q}_{\mathrm{r}}=0.15\right)$

$C$ - Case of $Q_{r}=0.20$

$d_{s}=0.349\left(\frac{H_{V} L_{V} \sin \alpha}{Y_{t}}\right)+9.2735$

The correlation coefficient is 0.70 . Fig. 14 , shows the regression curve. 


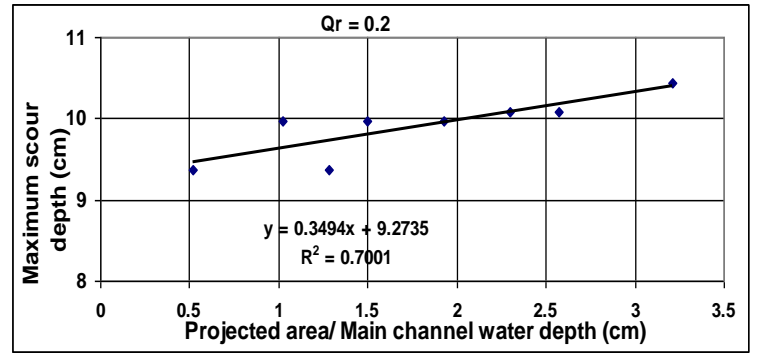

Fig. 14 Regression curve for maximum scour depth prediction $\left(\mathrm{b}_{\mathrm{v}} / \mathrm{b}_{\mathrm{d}}=0.5, \mathrm{Q}_{\mathrm{r}}=0.2\right)$

\section{$D$ - Case of $Q_{r}=0.30$}

$d_{s}=0.5934\left(\frac{H_{V} L_{V} \sin \alpha}{Y_{t}}\right)+8.1311$

The correlation coefficient is 0.9392 . Fig. 15 shows the regression curve.

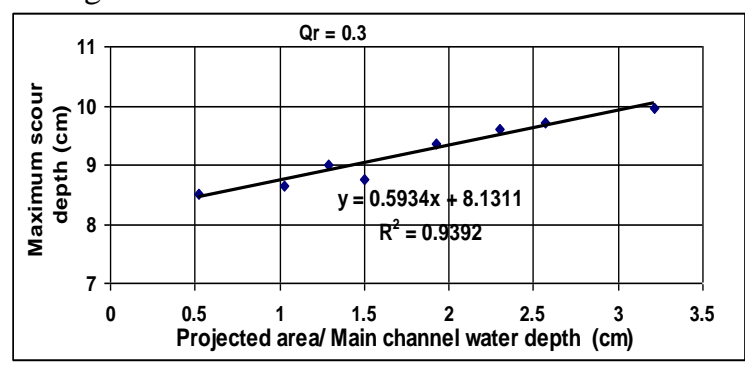

Fig. 15 Regression curve for maximum scour depth prediction $\left(b_{v} / b_{d}=0.5, Q_{r}=0.3\right)$

\section{$E$ - Case of $Q_{r}=0.10,0.15,0.20$ and 0.30}

The resulting formula reads as:

$d_{s}=8.2796\left(\frac{H_{V} L_{V} \sin \alpha}{Y_{t}}\right)^{0.1632}$

The correlation coefficient is 0.4098 . Fig. 16 shows the regression curve

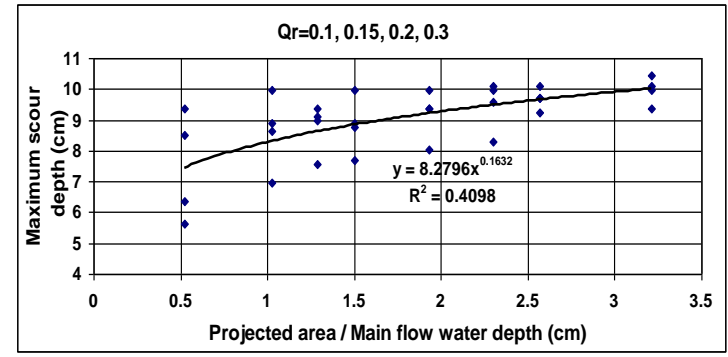

Fig. 16 Regression curve for maximum scour depth prediction $\left(b_{v} / b_{d}=0.5, Q_{r}=0.1,0.15,02,0.3\right)$

The previous results show that the correlation coefficients of the predicted formulas are satisfied in cases of using the test results of the used ratios of Qr, separately. In case of gathering all test results of the used ratios of the Qr, the correlation coefficients of the predicted formulas are not satisfied.
The previous equations show that, the equilibrium scour depth ds are practically proportional to the projected area of the vane, Ap. This complies with scour formulae for rectangular bridge piers with oblique approach flows, Simons and Senturk, (1992). In case of obstacles over the full flow depth, such as rectangular bridge piers, local scour usually increases with increasing flow depth, Chang, (1992).

The shapes of the scour holes around submerged vanes and bridge piers may seem appropriate. However, scour relations for bridge piers do not account for submergence, whereas the results of the present experiments indicate that the scour hole dimensions also depend on the ratio of initial vane height to flow depth. If $\mathrm{Yt} \leq \mathrm{Hv}$, a vane would act as a rectangular bridge pier with extremely small structural width and the maximum scour depth should increase with increasing flow depth. Maximum scour depths predicted by the equation for $\mathrm{Yt}=\mathrm{Hv}$.

\section{CONCLUSIONS}

Sixty experimental tests were carried out on a flume of $20 \mathrm{~m}$ long, $0.6 \mathrm{~m}$ width and $0.6 \mathrm{~m}$ depth to study the effect of different hydraulic condition and submerged vanes position, angle and height on the scour in front of intake channel. The tests were conducted at passing discharge through the intake channel of $0.10,0.15,0.20$ and 0.3 of the discharge passing through the main channel. The alignment of the row of vanes was located at five positions with respect to the intake bed width, bv/bd $=0.0,0.5,1.0$, 1.5, and 2.0. The angles of vanes with the main flow direction are changed five times, $\alpha=10^{\circ}, 20^{\circ}, 30^{\circ}$, $40^{\circ}$, and $50^{\circ}$. At some of the above mentioned angles of vanes, four heights of vanes are used, $\mathrm{Hv} / \mathrm{Yt}=0.2$, $0.3,0.4$, and 0.5 . The results of the above mentioned conditions are analyzed and used to show the effect of using single row of vanes with various situations on the scour in front of an intake channel.

Some of these different experimental arrangements are used to determine the maximum scour in front of the intake channel in case of using a single row of vanes with different angles, heights, $\mathrm{Qr}$ and at bv/bd $=0.50$. The results showed the following:

- The vanes have a clear effect on ds/dsw, when the value of Qr is less or equal 0.15.

- The effect of changing the values of bv/bd, $\alpha$ and $\mathrm{Hv} / \mathrm{Yt}$ at different $\mathrm{Qr}$ values were obvious on the scour in front of the intake channel.

- The maximum scour occurs at the pressure side of the vane near the leading edge for the lower angles of vanes with the main flow direction, but shifts towards the trailing edge with increasing angle of vanes.

- In order to assess the local scour at vicinity of vanes and to define the safe foundation for intake structure and the submerged vanes, five formulas were predicted under the conditions of 
$\mathrm{bv} / \mathrm{bd}=0.5$, water depth $=0.12 \mathrm{~m}, \alpha=\left(10^{\circ}\right.$, $20^{\circ}, 30^{\circ}, 40^{\circ}$, and $\left.50^{\circ}\right)$ and at $\mathrm{Qr}=0.10,0.15$, 0.20 and 0.3 .

- The predicted formulas at $\mathrm{Qr}=0.10,0.15,0.20$, 0.3 and gathering all the values of Qr, respectively, read as follows:

$\mathrm{d}_{\mathrm{s}}=1.8925 \ln \left(\mathrm{H}_{\mathrm{v}} * \mathrm{~L}_{\mathrm{v}} \sin \alpha / \mathrm{Y}_{\mathrm{t}}\right)+8.1863$,

$\mathrm{d}_{\mathrm{s}}=6.8471 \ln \left(\mathrm{H}_{\mathrm{v}} * \mathrm{~L}_{\mathrm{v}} \sin \alpha / \mathrm{Y}_{\mathrm{t}}\right)^{0.2753}$,

$\mathrm{d}_{\mathrm{s}}=0.349 \ln \left(\mathrm{H}_{\mathrm{v}} * \mathrm{~L}_{\mathrm{v}} \sin \alpha / \mathrm{Y}_{\mathrm{t}}\right)+9.274$

$\mathrm{d}_{\mathrm{s}}=0.5934 \ln \left(\mathrm{H}_{\mathrm{v}} * \mathrm{~L}_{\mathrm{v}} \sin \alpha / \mathrm{Y}_{\mathrm{t}}\right)+8.131$,

$\mathrm{d}_{\mathrm{s}}=8.280 \ln \left(\mathrm{H}_{\mathrm{v}} * \mathrm{~L}_{\mathrm{v}} \sin \alpha / \mathrm{Y}_{\mathrm{t}}\right)^{0.1632}$

\section{REFERENCES}

[1] Barkdoll, B. D., et al, (1999), “ Sediment control at lateral diversions: Limits and enhancements to vane use" j. Hydraul. Eng., 125(8), 862-870.

[2] Chang, H.H. (1992). "Fluvial processes in river engineering” Krieger Publ. Co., Florida, USA.

[3] Fahmy S. Abdel-Haleem (2008), "Sediment Control at Riverside Intake", M.Sc. thesis, Minoufiya University,

[4] Johnson, P. A., et al, (2001), “Use of vanes for control of scour at vertical wall abutments" $\mathrm{j}$. Hydraul. Eng., 127(9), 772-778.

[5] Michell, F., et al, (2006), “ Case study: Sediment control at water intake for large thermal-power station on a small river. " $\mathrm{j}$. Hydraul. Eng., 132(5), 440-449.

[6] Odgaard, A.J., and Kennedy, J. F., (1983), "River-bend bank protection by submerged vanes" j. Hydraul. Eng., 1109(8), 1161-1173.

[7] Odgaard, A.J., and Spoljaric, A., (1989), "Sediment control by submerged vanes: Dedign basis." River meandering, water resources monograph, No. 12, S. Ikeda and G. Parker, eds., American Geophysical Union, 127-151.

[8] Odgaard, A.J., and Wang Y. (1991a), "Sediment Management with Submerged Vanes. I: Theory", Journal of the Hydraulics Division, ASCE, vol. 117(3), 267-283.

[9] Odgaard, A.J., and Wang Y. (1991b), "Sediment Management with Submerged Vanes. II: Theory", J. Hydraul. Eng., 117(3), 284-302.
[10] Simons, D.B. and Sunturk, F. (1992). "Sediment transport technology, Water and sediment dynamics" Water Resources publication, USA,

[11] Vanoni, V.A. (1977). "Sedimentation Engineering" ASCE manuals and reports on engineering.

[12] Wang Y., and Odgaard, A.J., (1993), "Flow control with vorticity.", J. Hydraul. Res., 31(4), 549-562.

[13] Wang Y., et al., (1996), "Sediment control at water intakes." J. Hydraulic Eng., 122(6), 353356.

\section{LIST OF ABBREVIATIONS}

$A_{p} \quad$ Projected area of the Vane

$b_{m} \quad$ Main channel width

$b_{d} \quad$ Intake channel width

$b_{v}$ Distance from the centerline of the intake to the centerline of vane's row,

$d_{s} \quad$ Maximum scour depth at the front of the intake

$\mathrm{d}_{\mathrm{sw}} \quad$ Maximum scour depth at the front of the intake without submerged vanes

$\mathrm{d}_{50} \quad$ Median grain size of sediment

$\mathrm{F}_{\mathrm{r}} \quad$ Tail Froude number

g Gravitational acceleration

$\mathrm{H}_{\mathrm{v}} \quad$ Vane height above the bed

$\mathrm{L}_{\mathrm{v}} \quad$ Vane Length

$\mathrm{Q}_{\mathrm{d}}$ Discharge passing through the intake channel

$\mathrm{Q}_{\mathrm{m}} \quad$ Discharge passing through the main channel

$\mathrm{Q}_{\mathrm{r}} \quad$ Relative discharge $=\mathrm{Q}_{\mathrm{d}} / \mathrm{Q}_{\mathrm{m}}$

$Y_{t} \quad$ Tail water depth of the main channel

$\lambda \quad$ Kinetic-flow factor $=\mathrm{F}_{\mathrm{r}}{ }^{2}$

$\alpha \quad$ Angle of vanes with the direction of main flow

\section{ACKNOWLEDGMENTS}

This work was carried out at the Hydraulics Research Institute, HRI; National Water Research Center, Egypt. The authors gratefully acknowledge the collaboration and effort done by HRI Staff. 